\title{
Effects of Si on Tensile Properties Associated with Deformation-Induced $\varepsilon$-Martensitic Transformation in High Mn Austenitic Alloys
}

\author{
Motomichi Koyama ${ }^{1, *}$, Takahiro Sawaguchi ${ }^{2}$ and Kaneaki Tsuzaki ${ }^{1,2}$ \\ ${ }^{1}$ Kyushu University, Fukuoka 819-0395, Japan \\ ${ }^{2}$ National Institute for Materials Science, Tsukuba 305-0047, Japan
}

\begin{abstract}
We investigated the effect of $\mathrm{Si}$ on the tensile properties of Fe-33Mn, Fe-33Mn-4Si, and Fe-33Mn-6Si austenitic alloys (mass\%) at 273, 294, 323, and $423 \mathrm{~K}$. The Si addition promoted the deformation-induced $\varepsilon$-martensitic transformation, thereby enhancing the work-hardening capacity. In terms of Considère's criterion, the enhanced work-hardening capacity can improve uniform elongation. However, the Si addition simultaneously promoted brittle cracking associated with $\varepsilon$-martensite, tending toward decreasing elongation. As a result of the ambivalent roles of Si related to $\varepsilon$-martensite, the elongation-strength balance was improved by the addition of $4 \% \mathrm{Si}$, but was deteriorated when the Si content increased to $6 \%$. As an additional effect, the Si addition changed the microvoid-formation behavior, resulting in decreasing local elongations. [doi:10.2320/matertrans.M2015042]
\end{abstract}

(Received January 26, 2015; Accepted March 6, 2015; Published April 17, 2015)

Keywords: high manganese steel, austenitic steel, e-martensitic transformation, work hardening, brittle fracture

\section{Introduction}

High-Mn austenitic steels have various superior properties: ductility-strength balance, ${ }^{1-4)}$ shape memory effect, ${ }^{5-7)}$ and low cycle fatigue resistance. ${ }^{8-11)}$ These characteristic properties stem from the FCC $(\gamma) \rightarrow \operatorname{HCP}(\varepsilon)$ martensitic transformation. In particular, the embrittlement ${ }^{12-15}$ ) and work hardening behavior ${ }^{1,2,16-18)}$ associated with the $\varepsilon$-martensitic transformation are critical factors in controlling the mechanical properties of high-Mn steels.

From the viewpoint of work hardening, uniform elongation is determined by following Considère's criterion:

$$
\sigma \geq \mathrm{d} \sigma / \mathrm{d} \varepsilon
$$

$\sigma$ is the true stress and $\mathrm{d} \sigma / \mathrm{d} \varepsilon$ the work-hardening rate. As long as the fracture mechanism is ductile, necking occurs if eq. (1) is satisfied, causing failure through coalescence of microvoids. Ductile high Mn austenitic steels satisfy the relationship eq. (1) and correspondingly exhibit uniform elongation. ${ }^{19-23)}$ Since the deformation-induced $\varepsilon$-martensitic transformation enhances the work-hardening capacity markedly, the effect of $\varepsilon$-transformation-induced plasticity ( $\varepsilon$ TRIP) is expected to improve uniform elongation in terms of the suppression of local necking. Some enhanced mechanical properties realized by utilizing the $\varepsilon$-TRIP effect have actually been reported. ${ }^{16,20)}$

The other important factor dominating uniform elongation, namely embrittlement, must also be considered here. Equation (1) is not satisfied in case of brittle fracture. The $\varepsilon$-martensitic transformation possibly causes $\gamma / \varepsilon$ interface cracking, ${ }^{12)}$ intergranular cracking, ${ }^{15,20)}$ and annealing twin boundary cracking. ${ }^{13,14)}$ These brittle cracking phenomena need to be suppressed for the advantageous utilization of the $\varepsilon$-martensitic transformation. For instance, brittle cracking has been suppressed through grain refinement ${ }^{15,20)}$ and deformation-induced reverse transformation, ${ }^{9,18)}$ improving the ductility-strength balance.

*Corresponding author, E-mail: koyama@mech.kyushu-u.ac.jp
The above mentioned work hardening and embrittlement depend on the characteristics of $\varepsilon$-martensite, e.g., thermal stability, mechanical properties, distribution/morphology, and volume fraction. Furthermore, these factors show distinct deformation temperature and chemical composition dependence. With respect to chemical composition, the addition of Si remarkably changes the $\varepsilon$-martensitic transformation behavior and its associated mechanical properties. ${ }^{3,4,16,24-27)}$ Additionally, $\varepsilon$-martensite with a high amount of $\mathrm{Si}(>6$ mass \%) has been reported to cause embrittlement. ${ }^{6,12,24,28)}$ Namely, the optimization of the $\mathrm{Si}$ concentration is an effective material-design strategy toward the beneficial utilization of $\varepsilon$-martensite. In order to understand the effects of $\mathrm{Si}$ incorporation, analyses on work hardening are required for discussing the deformation behavior and fractographic analyses provide important information about the local damage evolution associated with embrittlement or necking. However, the influences of varying Si concentration on the occurrence of premature fracture and enhanced work hardening have not been investigated well in terms of Considère's criterion and fracture-surface features in case of tensile deformations. Hence, this study aims at clarifying the metallurgical influences of varying $\mathrm{Si}$ concentration on $\varepsilon$ martensite-related mechanical properties through detailed analyses of stress-strain responses and fracture behavior. More specifically, we separately discuss the Si effects on yielding, work hardening, necking, cracking, and void formation/coalescence in the Fe-33Mn-xSi system which is the typical base composition of shape memory austenitic alloys. ${ }^{6}$

\section{Experimental}

Fe-33Mn, Fe-33Mn-4Si, and Fe-33Mn-6Si (mass\%) alloys were produced by vacuum induction melting. The ingots were hot forged and rolled at $1273 \mathrm{~K}$. The rolled bars were solution-treated at $1273 \mathrm{~K}$ for $1 \mathrm{~h}$, and subsequently water quenched to suppress uncontrolled second-phase formation. The detailed chemical compositions are shown in Table 1. 
Table 1 Chemical composition and transformation and Néel temperatures $M_{\mathrm{S}}$ and $T_{\mathrm{N}}$, respectively, of the presently investigated alloys. The accuracy of $M_{\mathrm{S}}$ of the Fe-30Mn-4Si alloy may be reduced because the change of Young's modulus around $M_{\mathrm{s}}$ is much less pronounced than that of the $\mathrm{Fe}$ 30Mn-6Si alloy (compare with Fig. 1).

\begin{tabular}{cccccc}
\hline $\begin{array}{c}\text { Alloy } \\
(\text { mass\% })\end{array}$ & Mn & Si & Fe & $M_{\mathrm{S}}(\mathrm{K})$ & $T_{\mathrm{N}}(\mathrm{K})$ \\
\hline Fe-33Mn & 32.6 & - & Bal. & - & 390 \\
Fe-33Mn-4Si & 33.0 & 3.96 & Bal. & 266 & 336 \\
Fe-33Mn-6Si & 32.7 & 6.00 & Bal. & 264 & 282 \\
\hline
\end{tabular}

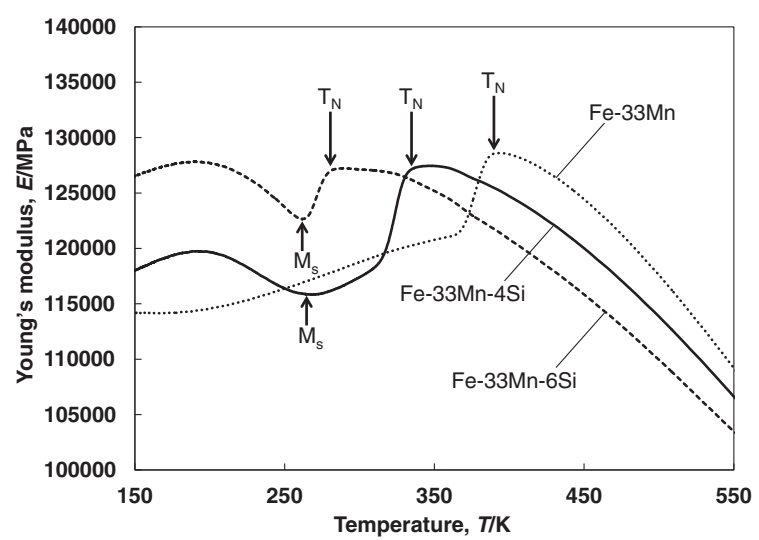

Fig. 1 Temperature dependence of Young's modulus obtained by DMA for the Fe-33Mn, Fe-33Mn-4Si, and Fe-33Mn-6Si alloys.

The binary Fe-33Mn alloy shows no $\varepsilon$-martensitic transformation at room temperature and maintains its single austenite phase even after fracture. ${ }^{23)}$ On the other hand, the undeformed microstructure of the Fe-33Mn-6Si alloy is fully austenite, and the deformed microstructure contains a considerable amount of $\varepsilon$-martensite. ${ }^{6,25)}$ The martensitic transformation and Néel temperatures $M_{\mathrm{S}}$ and $T_{\mathrm{N}}$, respectively, were measured by dynamic mechanical analysis (DMA, TA instruments model 2980). The temperature dependence of Young's modulus obtained by DMA provides the transformation temperatures. ${ }^{27,29,30)}$ During the cooling process of the DMA, thermally induced $\varepsilon$-martensite increases Young's modulus whereas the antiferromagnetic transition decreases it. The obtained temperature dependence of Young's modulus and the corresponding transformation temperatures are shown in Fig. 1 and Table 1, respectively. Since the $M_{\mathrm{S}}$ of the Fe-33Mn-6Si alloy and the $T_{\mathrm{N}}$ of the Fe-32Mn-6Si alloy have been reported to be $264^{25}$ and $284 \mathrm{~K},{ }^{31)}$ respectively, the presently measured transformation temperatures are in good agreement with the reported values.

The deformation temperature ranging from $123 \mathrm{~K}$ to $423 \mathrm{~K}$ was controlled by a thermostatic chamber installed on the tensile machine. The elongation and strength of the specimens with dimensions of $\mathrm{w} 4.0 \mathrm{~mm} \times \mathrm{t} 1.0 \mathrm{~mm} \times 130.0 \mathrm{~mm}$ with a grip section at both ends were obtained from the tensile tests conducted at the initial strain rate of $1.7 \times$ $10^{-4} \mathrm{~s}^{-1}$ along the rolling direction. The elongation was determined by measuring the gauge length before and after the tensile test. All stress-strain curves obtained from the load-displacement data were fitted to the elongations that were evaluated from the change in gauge length.

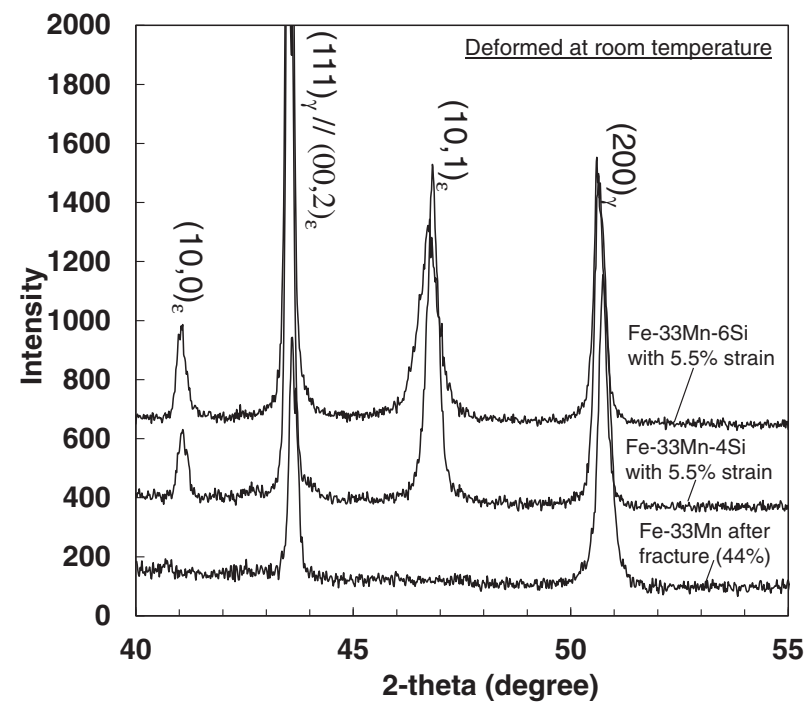

Fig. 2 XRD patterns of specimens deformed at room temperature.

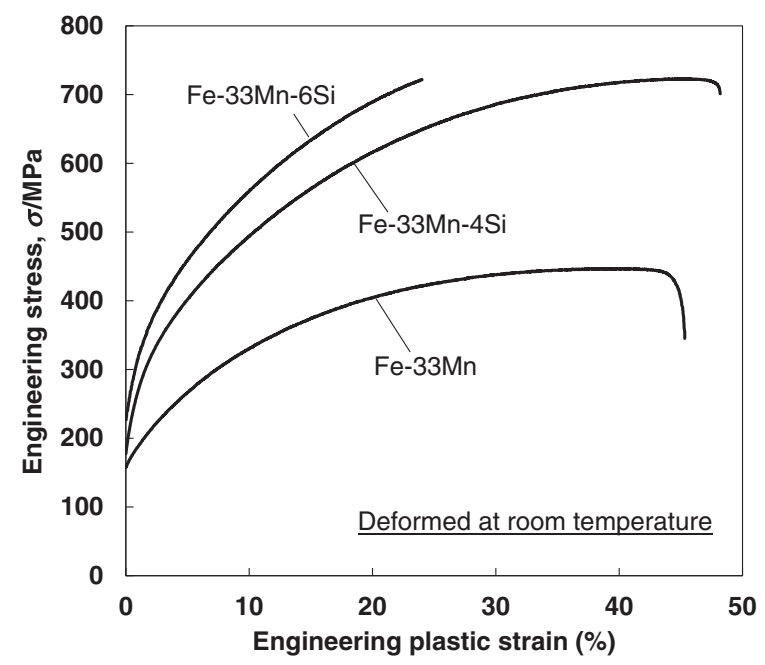

Fig. 3 Engineering stress-strain curves at room temperature.

X-ray diffractometry (XRD) was carried out to determine the microstructures after deformation. The specimens for the XRD measurements were chemically polished $\left(\mathrm{H}_{2} \mathrm{O}_{2}: \mathrm{HF}=\right.$ $10: 1)$ at $294 \mathrm{~K}$ (room temperature) after mechanical polishing. All XRD measurements were carried out in normal direction (with respect to the specimen surface) at $35 \mathrm{kV}$, $300 \mathrm{~mA}$, and scan rate of $0.02^{\circ} \mathrm{s}^{-1}$ using a $\mathrm{Cu}$ target. In addition, the fracture surfaces were observed by scanning electron microscopy (SEM) operated at $20 \mathrm{kV}$.

\section{Results and Discussion}

\subsection{Stress-strain response associated with $\varepsilon$-martensite}

First, we focus on the formation of $\varepsilon$-martensite and its associated stress-strain responses at room temperature. During deformation at room temperature, the Fe-33Mn-4Si and $\mathrm{Fe}-33 \mathrm{Mn}-6 \mathrm{Si}$ alloys reveal the presence of $\varepsilon$-martensite, in contrast to Fe-33Mn alloy, as evident from the XRD patterns shown in Fig. 2. Namely, the addition of Si promotes the $\varepsilon$-martensitic transformation.

Figure 3 shows engineering stress-strain curves at room temperature of the Fe-33Mn, Fe-33Mn-4Si, and Fe-33Mn- 
$6 \mathrm{Si}$ alloys. The results indicate that flow stress and workhardening capacity increase with increasing Si content. Since the main difference among these alloys is the presence of $\varepsilon$-martensite, as indicated in Fig. 2, the enhanced work hardening stems from the Si-promoted $\varepsilon$-martensitic transformation. On the other hand, the effect of $\mathrm{Si}$ on elongation is relatively complicated, namely, the uniform elongation increased by the addition of $4 \%$ of $\mathrm{Si}$ and deteriorated remarkably on further increasing the Si concentration to $6 \%$. Additionally, the stress-strain curve of Fe-33Mn-6Si did not show any significant local elongation. It is considered that the enhanced work-hardening capacity increased the uniform elongation, whereas the occurrence of premature fracture associated with $\varepsilon$-martensite decreased the uniform and local elongations. The increase and decrease in elongation with increasing Si content will be discussed later on the basis of detailed analyses of the work-hardening behavior and fractographs.

Next, the deformation temperature dependence of the stress-strain responses is shown in Fig. 4. All investigated alloys showed decreasing flow stress and work-hardening capacity on increasing deformation temperature. In particular, the Fe-33Mn-4Si and Fe-33Mn-6Si alloys showed pronounced reductions in their work-hardening capacity with increasing deformation temperature. In order to analyze the details the effects of Si content and deformation temperature on the mechanical responses, we have to separately consider different regions of the stress-strain curves: $0.2 \%$ proof stress, work-hardening rate, uniform elongation, and local elongation.

\subsection{Factors dominating the $0.2 \%$ proof stress}

Figure 5 shows the dependence of the $0.2 \%$ proof stress of the three investigated alloys on deformation temperature. The Fe-33Mn alloy in which $\varepsilon$-martensite does not form showed a monotonic decrease in $0.2 \%$ proof stress with increasing deformation temperature. This reduction in $0.2 \%$ proof stress is explained by the promotion of slip deformations associated with thermally activated dislocation motions. In contrast, the Fe-33Mn-4Si and Fe-33Mn-6Si alloys showed increasing $0.2 \%$ proof stress with increasing deformation temperature in the range from 273 to $373 \mathrm{~K}$, but decreasing values with further increasing temperature in the range from 373 to $423 \mathrm{~K}$. Although the latter trend is also explained by the thermal activation process of dislocation motions, the former trend requires the consideration of the critical stress for the deformation-induced $\varepsilon$-martensitic transformation. The critical stress for the deformation-induced $\varepsilon$-martensitic transformation is controlled by the difference in enthalpy between the $\gamma$ and $\varepsilon$ phase. According to the Clausius-Clapeyron equation, the $0.2 \%$ proof stress increases with increasing deformation temperature as long as yielding is dominated by the initiation of the $\varepsilon$-martensitic transformation (for a more quantitative understanding, this consideration needs to be modified according to a recent work $\left.{ }^{32}\right)$. In other words, the peaks of the $0.2 \%$ proof stress against temperature $(373 \mathrm{~K})$ in both Si-containing alloys reflect the temperature $M_{\mathrm{s}}{ }^{\sigma}$ which corresponds to the boundary between $\varepsilon$-martensitic transformation-dominated and slip deformation-dominated yielding.
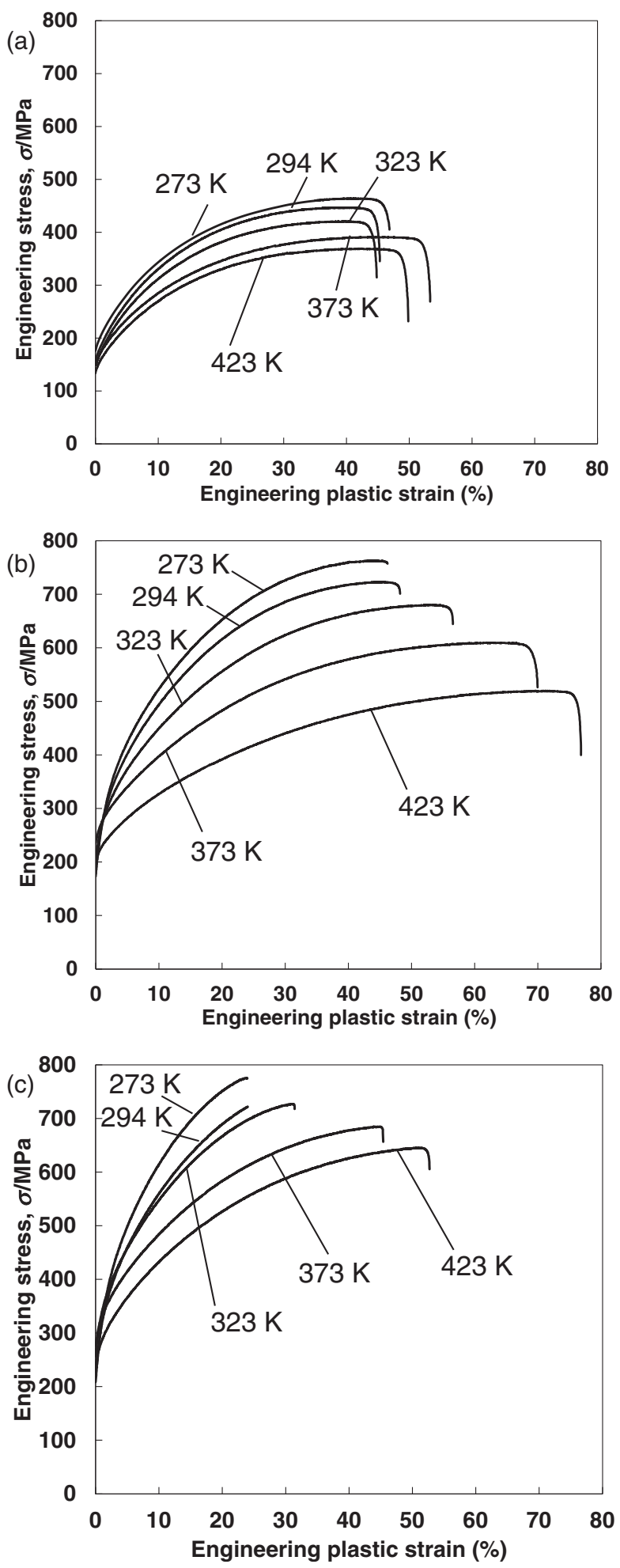

Fig. 4 Engineering stress-strain curves at various deformation temperatures of (a) Fe-33Mn, (b) Fe-33Mn-4Si, and (c) Fe-33Mn-6Si alloys.

The Si concentration dependence of the $0.2 \%$ proof stress is attributed to the thermal stability of the $\gamma$ phase and the high degree of solution hardening. ${ }^{25,27)}$ Since the thermal stability of $\gamma$ decreases with decreasing deformation temperature, the $0.2 \%$ proof stress of the $\mathrm{Fe}-33 \mathrm{Mn}-4 \mathrm{Si}$ alloy at $273 \mathrm{~K}$, which is the lowest deformation temperature in the present study, is lower than that of the Fe-33Mn alloy at the same temperature. In contrast, the $0.2 \%$ proof stress at $423 \mathrm{~K}$ monotonically increases with increasing Si concentration, 


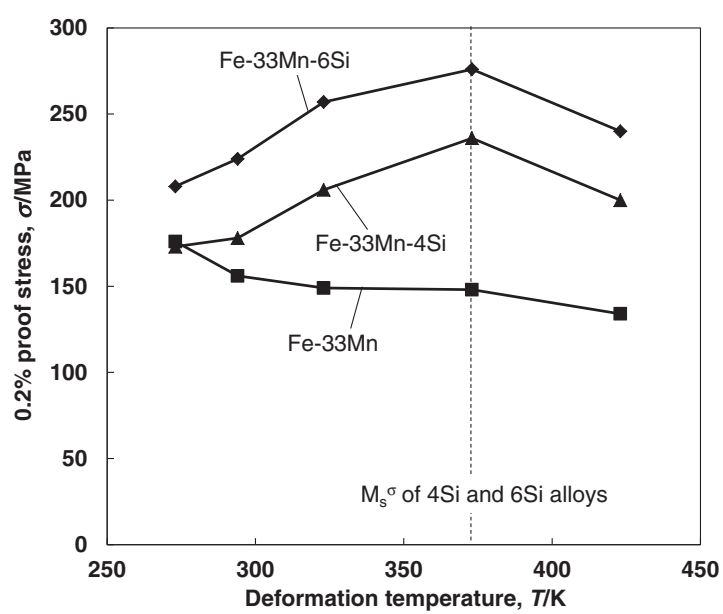

Fig. $50.2 \%$ proof stress plotted against deformation temperature.

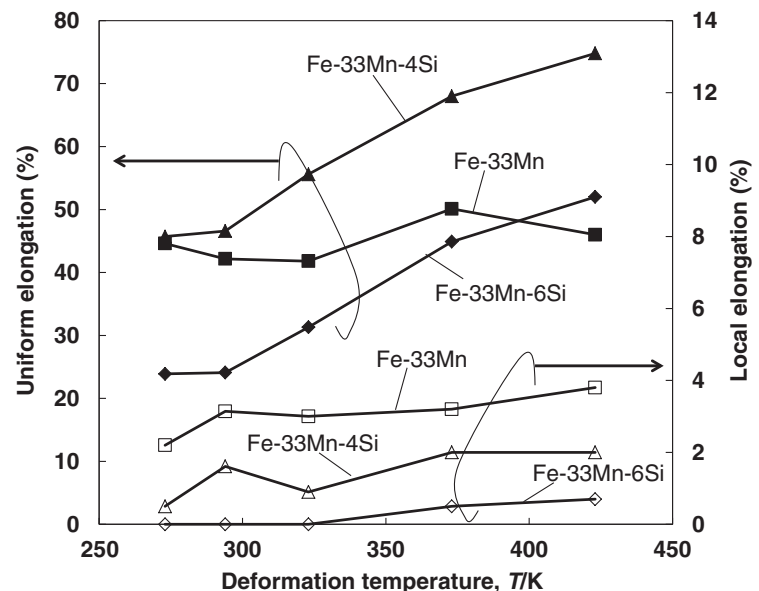

Fig. 6 Dependence of the uniform and local elongations on deformation temperature.

because only the effect of solution hardening contributes above $M_{\mathrm{s}}{ }^{\sigma}$.

\subsection{Elongation and work hardening}

Figure 6 shows the deformation-temperature dependence of uniform and local elongations. The influence of the deformation temperature on elongation in the Fe-33Mn alloy is relatively small compared to the $\mathrm{Si}$-containing alloys. The Fe-33Mn-4Si and Fe-33Mn-6Si alloys showed remarkable increases of the uniform elongation with increasing deformation temperature. No significant local elongation was observed at $273 \mathrm{~K}$ in the Fe-33Mn-4Si and Fe-33Mn-6Si alloys. Local elongations appeared above room temperature in Fe-33Mn-4Si alloy, and at $373 \mathrm{~K}$ in the Fe-33Mn-6Si alloy. First, we discuss the changing trends in uniform elongation by using eq. (1) as follows.

Figure 7 shows the true stress and work-hardening rate against true plastic strain at various deformation temperatures of the three alloys. The intersections of the work hardening and true stress-strain curves indicate plastic instability, expressed by eq. (1). Namely, if fracture occurs before reaching the intersection means occurrence of premature fracture. In other words, satisfying the plastic instability condition means occurrence of necking followed by fracture. The Fe-33Mn and Fe-33Mn-4Si alloys satisfy the plastic
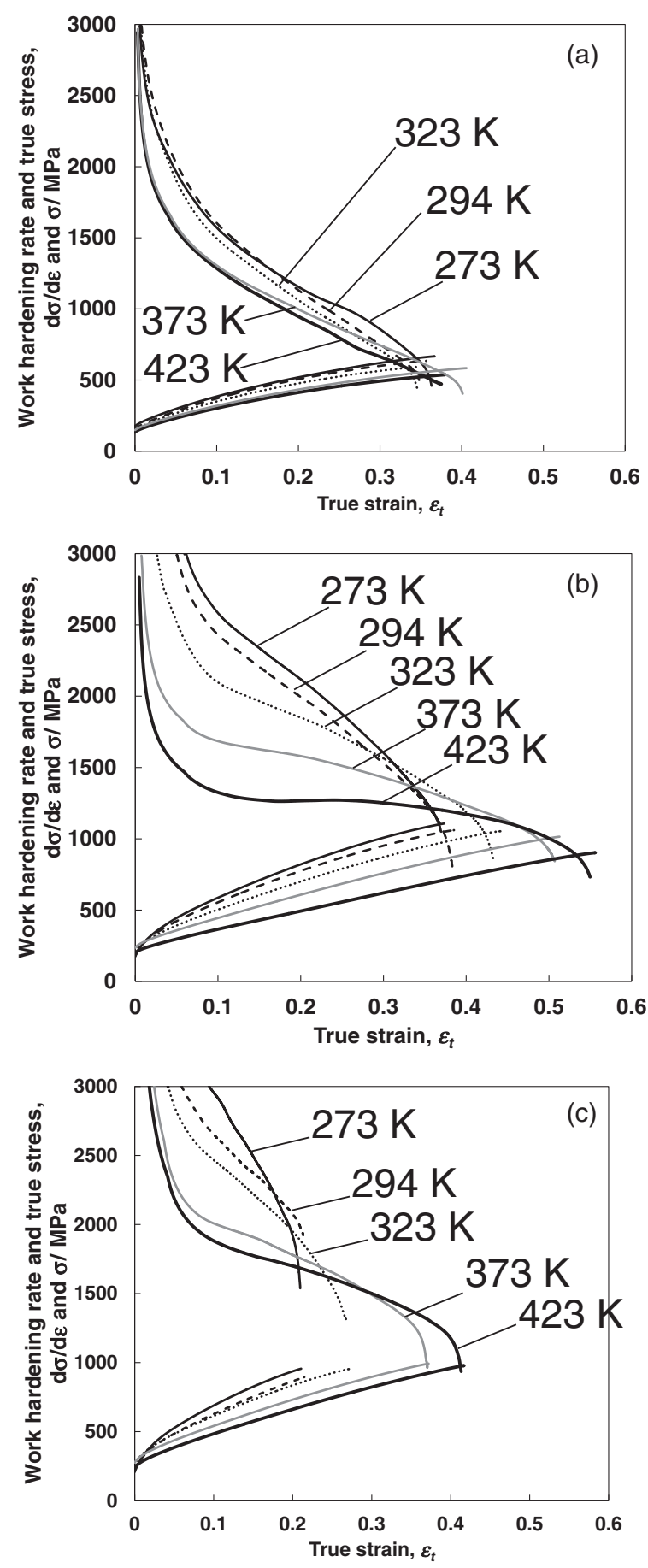

Fig. 7 Work hardening and true stress-strain curves for (a) Fe-33Mn, (b) Fe-33Mn-4Si, and (c) Fe-33Mn-6Si alloys.

instability condition, irrespective of the deformation temperature. In contrast, the $\mathrm{Fe}-33 \mathrm{Mn}-6 \mathrm{Si}$ alloy shows premature fracture below $373 \mathrm{~K}$. Additionally, the required strain to fulfill the plastic instability condition in the Fe-33Mn alloy does not change distinctly with increasing deformation temperature, and increased in case of the Fe-33Mn-4Si alloy. These facts indicate that the temperature dependence of uniform elongation is totally explained by Considère's criterion and the occurrence of premature fracture. Furthermore, it is noted that the Fe-33Mn-4Si alloy did not show significant local elongations at room temperature, although the plastic instability condition was satisfied. This indicates 

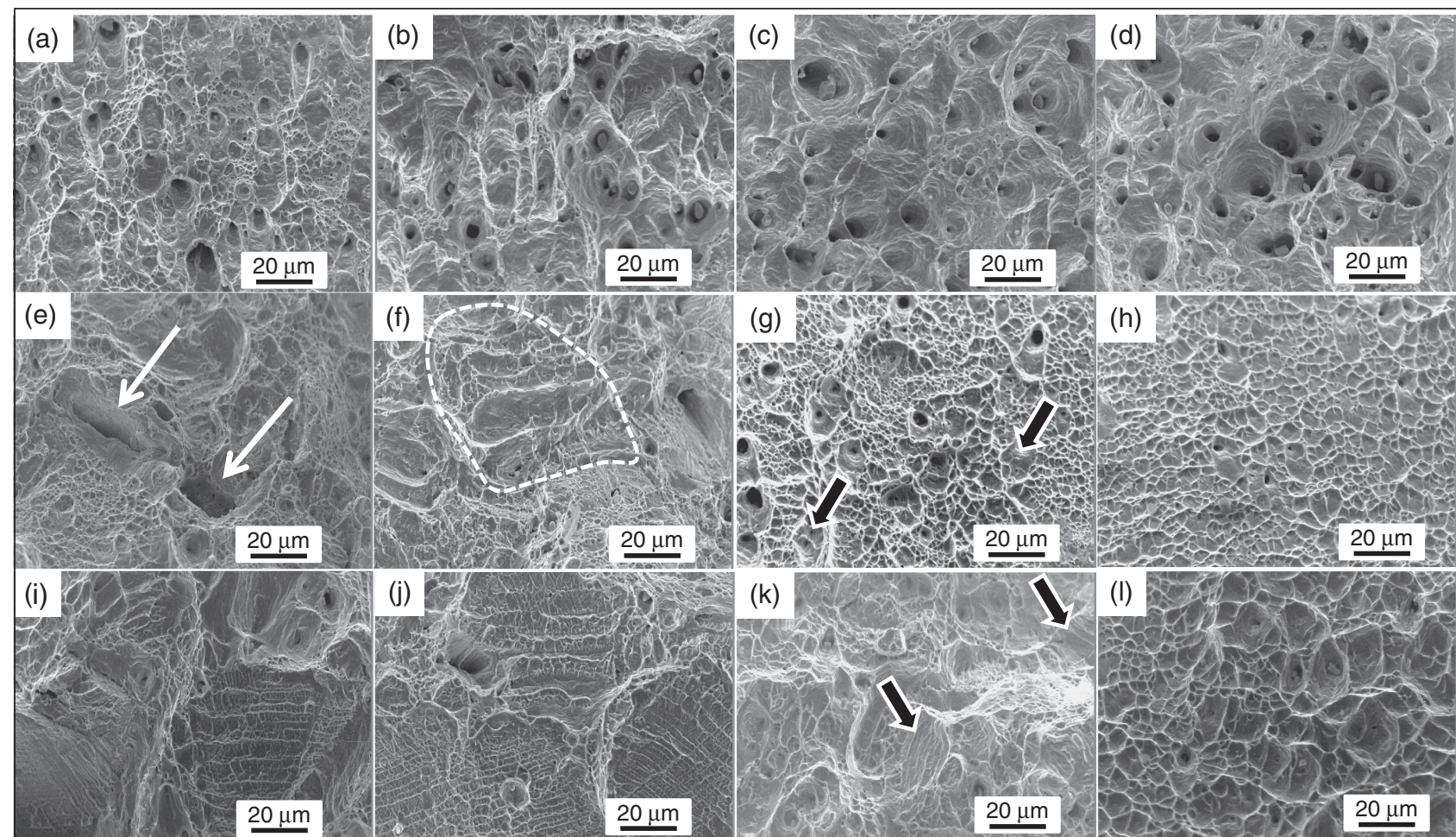

Fig. 8 Fractographs at (a) 273, (b) 294, (c) 373, and (d) $423 \mathrm{~K}$ of the Fe-33Mn alloy, at (e) 273, (f) 294, (g) 373 , and (h) 423 K of the Fe$33 \mathrm{Mn}-4 \mathrm{Si}$ alloy, and at (i) 273, (j) 294, (k) 373, and (l) $423 \mathrm{~K}$ of the Fe-33Mn-6Si alloy.

that brittle cracking occurs immediately after meeting the plastic instability condition, thereby decreasing the local elongation. The detailed discussion on local elongation requires fractographic analyses, as demonstrated in the next section.

\subsection{Fractographic characteristics}

Figure 8 shows fractographs obtained subsequently to the tensile tests shown in Fig. 4. The Fe-33Mn binary alloy showed ductile fracture characterized by the formation of dimples, irrespective of the deformation temperature, indicating that the fracture mechanism of the Fe-33Mn alloy is totally ductile in the present temperature range.

The Fe-33Mn-4Si and Fe-33Mn-6Si alloys show features of combined brittle and ductile fracture at and below $M_{\mathrm{s}}{ }^{\sigma}$ $(373 \mathrm{~K})$. In case of the Fe-33Mn-4Si alloy at $273 \mathrm{~K}$, the fracture surface indicates the occurrence of intergranular cracking as shown by the white arrow in Fig. 8(e). It has been reported that stress concentration at a tip of $\varepsilon$-martensite easily induces intergranular fracture in high Mn steels. ${ }^{12,14,15)}$ The fracture mode changes to quasi-cleavage when the temperature increases above $294 \mathrm{~K}$, as indicated by the white dotted lines in Fig. 8(f). This fracture surface is typically observed when cracking occurs along austenite $/ \varepsilon$-martensite interfaces. ${ }^{12)}$ When the deformation temperature reaches $373 \mathrm{~K}$, brittle features were observed only at some locations, indicated by black arrows in Fig. $8(\mathrm{~g})$ and $(\mathrm{k})$. At $423 \mathrm{~K}$, the fracture surface becomes totally ductile, like in case of the Fe-33Mn alloy.

The quasi-cleavage fracture surface at 273 and $294 \mathrm{~K}$ of the $\mathrm{Fe}-33 \mathrm{Mn}-6 \mathrm{Si}$ alloy contains step-like ridges, as shown in Figs. 8(i) and (j). The interspacing of these step-like ridges is finer and shallower than in case of the Fe-33Mn-4Si alloy

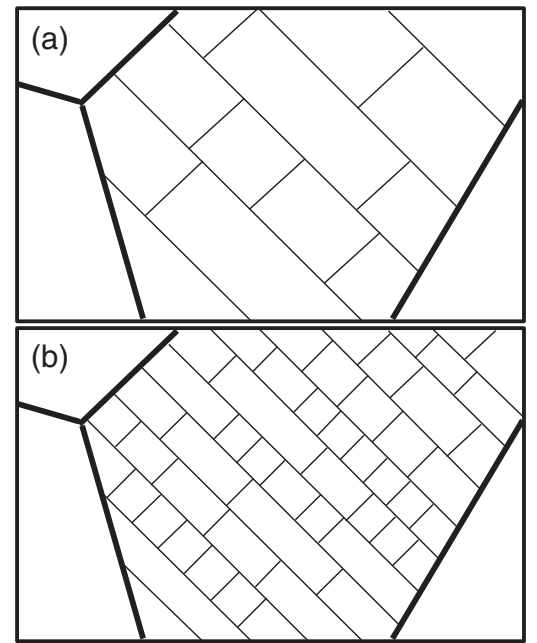

Fig. 9 Schematics of the features of quasi-cleavage fracture observed in (a) Fe-33Mn-4Si and (b) Fe-33Mn-6Si alloys.

(Fig. 8(f)). Figure 9 shows the schematic features of the fracture surface including the step-like ridges in the Fe$33 \mathrm{Mn}-4 \mathrm{Si}$ and Fe-33Mn-6Si alloys. Since the brittle-like ridges are considered to stem from microvoid formation associated with strain or stress concentrations along the $\gamma / \varepsilon$ interfaces, the presence of brittle features with finer lamellae implies that the addition of $6 \%$ of Si promotes $\gamma / \varepsilon$ interface cracking. Accordingly, the area fraction of brittle fracture features increased with increasing Si content, as shown in Fig. 10. The promotion of $\gamma / \varepsilon$ interface cracking is the main cause of the premature fracture shown in Fig. 7(c).

From the viewpoint of local elongation, ductile features also have to be taken into account to understand the fracture 


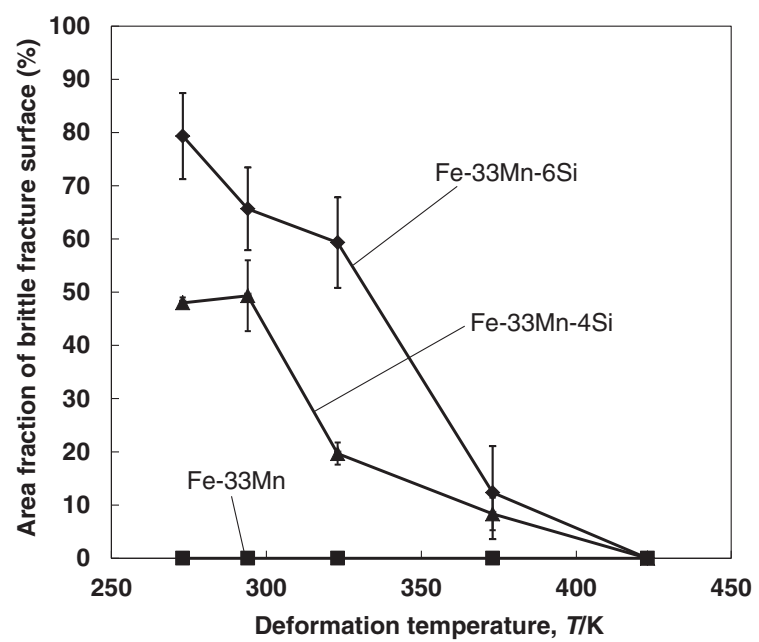

Fig. 10 Area fraction of the brittle fracture surface plotted against deformation temperature.

behavior in dependence of $\mathrm{Si}$ content and deformation temperature. Ductile fracture-surface images and average dimple sizes are shown in Figs. 11 and 12. The dimple sizes of the fracture surfaces decreased by the addition of $4 \%$ of $\mathrm{Si}$. The further addition of $\mathrm{Si}$ to the concentration of $6 \%$ did not change the average dimple size significantly. The decrease in dimple size by the addition of $\mathrm{Si}$ is clearly evident at $423 \mathrm{~K}$, which is a higher temperature than $M_{\mathrm{s}}{ }^{\sigma}$ for all alloys investigated in this study. Additionally, the dimples can be classified into two types: dimples with and without fisheyes. The size of the dimples with fisheye was significantly larger than that of the dimples without fisheyes. Dimples without fisheye were mainly observed in ductile fracture surfaces in the Fe-33Mn-4Si and Fe-33Mn-6Si alloys, as shown in Figs. 8(h) and (i), and were observed between dimples with fisheye in case of the Fe-33Mn alloy. The dimples with and without fisheyes are considered to arise from typical void formation initiated by inclusions and dislocation/dislocation interaction-induced vacancy/microvoid formation, respectively. The ductile fracture features observed for the Fe-33Mn alloy imply that the relatively small dimples without fisheye are formed to provide a linkage between the microvoids initiated from inclusions (dimples with fisheyes). On the other hand, the ductile fracture of the Fe-33Mn-4Si and Fe$33 \mathrm{Mn}-6 \mathrm{Si}$ alloys was dominated by dislocation/dislocation interaction-induced vacancy/microvoid formation/coalescence. A possible reason why dislocation/dislocation interaction-induced vacancy/microvoid formation dominated the ductile fracture of the Fe-33Mn-4Si and Fe-33Mn-6Si alloys is the reduction in stacking fault energy, which has been reported to decrease by the addition of $\mathrm{Si}^{11,33)}$ The reduction in stacking fault energy suppresses cross slips, thereby decreasing the frequency of recovery. The suppression of recovery increases the increasing rate of dislocation density and promotes vacancy formation, a process that can grow until the emergence of microvoids. As a result, the addition of $\mathrm{Si}$ caused dislocation/dislocation interaction-induced vacancy/microvoid formation prior to the typical microvoid formation. Since the microvoids grown from vacancies are smaller than those grown from inclusions, the dimple size decreased by the addition of Si. Assuming that both vacancy
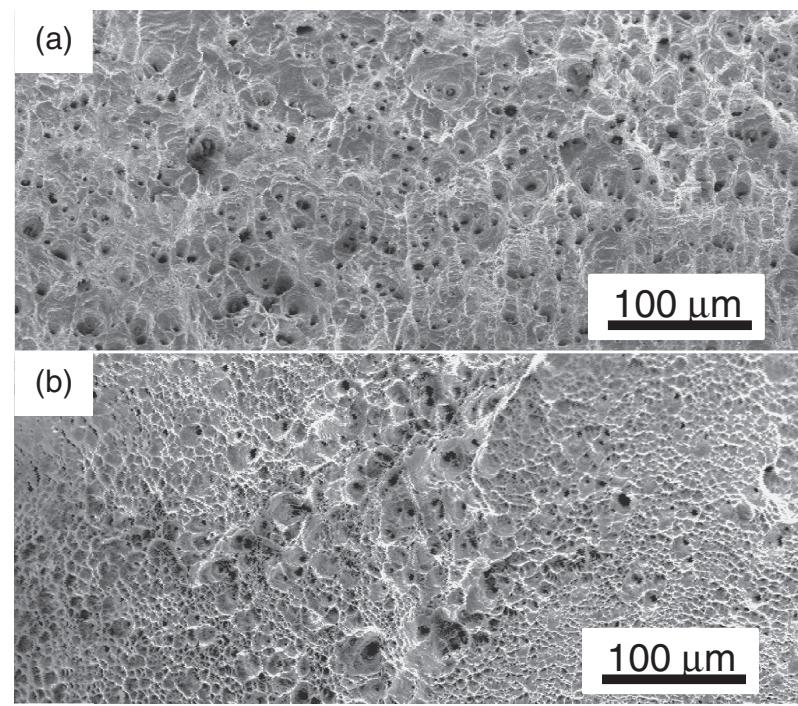

(c)

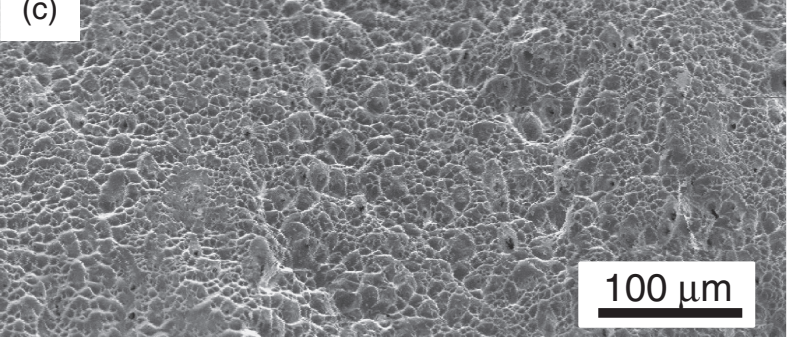

Fig. 11 Fractographs at low magnification of (a) Fe-33Mn, (b) Fe-33Mn$4 \mathrm{Si}$, and (c) Fe-33Mn-6Si alloys deformed at $423 \mathrm{~K}$.

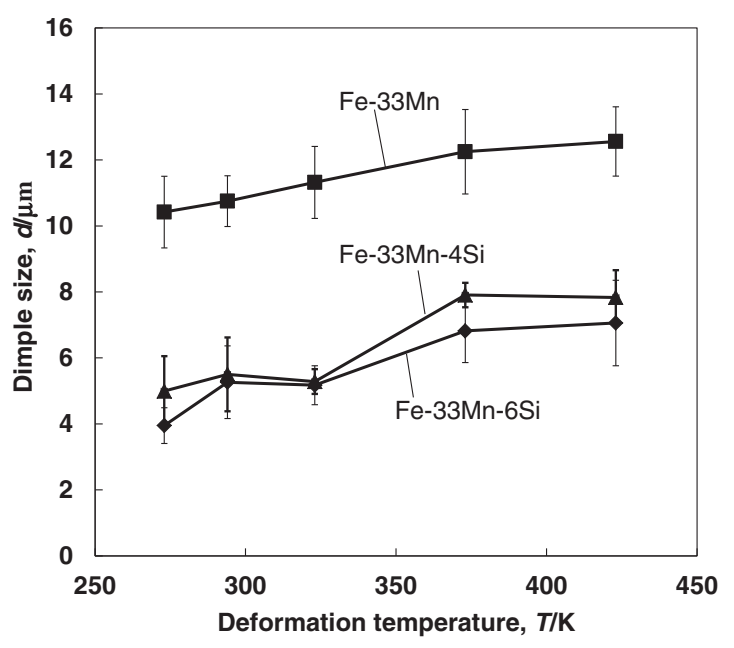

Fig. 12 Deformation-temperature dependence of the dimple size.

and microvoid formation are promoted even before the plastic instability condition is taking effect, the change in the ductile fracture mechanism by the addition of Si can be the reason for the accompanying decrease in local elongation (Fig. 6), even at $423 \mathrm{~K}$ where only ductile features were observed on the fracture surface.

In terms of elongation-strength balance, the effect of increasing Si content is not monotonic, as shown in Fig. 13. As mentioned above, the elongation-strength balance is a result of competing effects induced by $\mathrm{Si}$ incorporation: the change in the work-hardening capacity associated with the thermal stability of the $\gamma$ phase and the extension of 


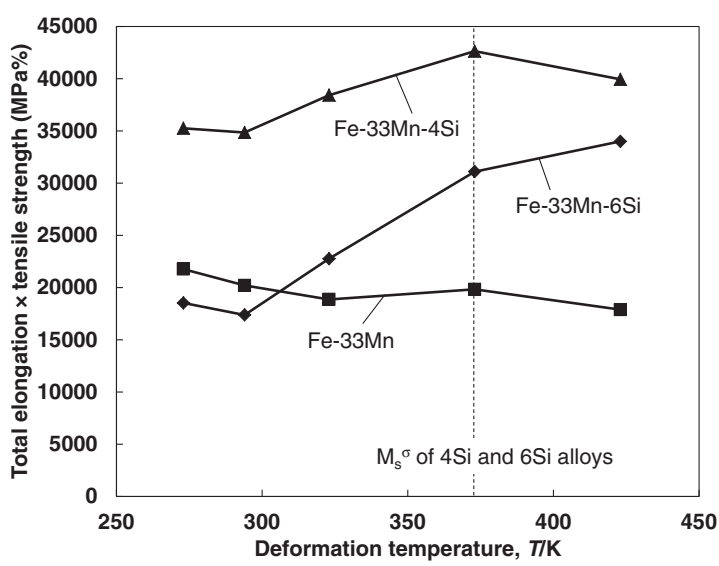

Fig. 13 Elongation-strength balance plotted against deformation temperature.

dislocations, the degree of solution hardening, easiness of brittle cracking, and microvoid formation behavior. All these factors affect the plastic instability condition, critical stress for premature fracture, and necking behavior, thus determining the final output in terms of elongation-strength balance. Considering all these facts, the Fe-33Mn-4Si alloy showed optimal elongation-strength balance in this study.

\section{Conclusions}

In this study, we clarified the influences of $\mathrm{Si}$ incorporation on the $\varepsilon$-martensite-related tensile properties in Fe-33Mn- $x \mathrm{Si}$ alloys. The respective effects of $\mathrm{Si}$ on the $0.2 \%$ proof stress, work-hardening capacity, uniform elongation, and local elongation are as follows.

(1) The $0.2 \%$ proof stress depends on the degree of solution hardening and thermal stability of the $\gamma$ phase against deformation-induced $\varepsilon$-martensitic transformation.

(2) Since the addition of $\mathrm{Si}$ promotes the $\varepsilon$-martensitic transformation, the work-hardening capacity is enhanced remarkably. As a result, uniform elongation and tensile strength are improved when the fracture type is ductile. However, $\mathrm{Si}$ addition also promotes the occurrence of brittle cracking associated with $\varepsilon$-martensite, thereby causing premature fracture. The premature fracture decreases uniform elongation. In detail, the effect of $\mathrm{Si}$ on the $\varepsilon$-martensitic transformation results in ambivalent roles on the uniform elongation.

(3) The $\mathrm{Si}$ addition changes the microvoid-formation behavior. In addition, the brittle cracking associated with $\varepsilon$-martensite can occur even after the plastic instability condition has been satisfied. Hence, the difference in the microvoid-formation behavior and the occurrence of brittle cracking decrease the local elongation.

\section{Acknowledgements}

The authors are grateful to the Materials Manufacturing and Engineering Station and Materials Analysis Station at the National Institute for Materials Science for supporting this work by preparing the samples and performing the analysis of the chemical compositions. This work was supported by JSPS KAKENHI Grant Number 25249099.

\section{REFERENCES}

1) Y. Tomota, M. Strum and J. W. Morris: Metall. Trans. A 17 (1986) 537-547.

2) L. Remy and A. Pineau: Mater. Sci. Eng. 28 (1977) 99-107.

3) M. Koyama, M. Murakami, K. Ogawa, T. Kikuchi and T. Sawaguchi: J. Jpn. Inst. Metals 71 (2007) 502-507.

4) M. Koyama, M. Murakami, K. Ogawa, T. Kikuchi and T. Sawaguchi: Mater. Trans. 48 (2007) 2729-2734.

5) A. Sato, E. Chishima, K. Soma and T. Mori: Acta Metall. 30 (1982) 1177-1183.

6) M. Murakami, H. Otsuka, H. G. Suzuki and S. Matsuda: Proc. Int. Conf. Martensitic Transformations, (Japan Inst. Metals, Nara, 1986) p. 985.

7) M. Koyama, T. Sawaguchi and K. Tsuzaki: J. Alloy. Compd. 573 (2013) 15-19.

8) T. Sawaguchi, P. Sahu, K. Ogawa, S. Kajiwara, A. Kushibe, M. Higashino and T. Ogawa: Scr. Mater. 54 (2006) 1885-1890.

9) T. Sawaguchi, L.-G. Bujoreanu, T. Kikuchi, K. Ogawa, M. Koyama and M. Murakami: Scr. Mater. 59 (2008) 826-829.

10) I. Nikulin, T. Sawaguchi and K. Tsuzaki: Mater. Sci. Eng. A 587 (2013) $192-200$.

11) T. Sawaguchi, I. Nikulin, K. Ogawa, K. Sekido, S. Takamori, T. Maruyama, Y. Chiba, A. Kushibe, Y. Inoue and K. Tsuzaki: Scr. Mater. (2015).

12) S. Takaki, T. Furuya and Y. Tokunaga: ISIJ Int. 30 (1990) 632-638.

13) M. Koyama, T. Sawaguchi and K. Tsuzaki: ISIJ Int. 52 (2012) 161-163.

14) M. Koyama, T. Sawaguchi and K. Tsuzaki: Metall. Mater. Trans. A 43 (2012) 4063-4074.

15) M. Koyama, T. Lee, C. S. Lee and K. Tsuzaki: Mater. Des. 49 (2013) 234-241.

16) O. Grässel, L. Krüger, G. Frommeyer and L. W. Meyer: Int. J. Plasticity 16 (2000) 1391-1409.

17) M. Koyama, T. Sawaguchi, T. Lee, C. S. Lee and K. Tsuzaki: Mater. Sci. Eng. A 528 (2011) 7310-7316.

18) M. Koyama, T. Sawaguchi and K. Tsuzaki: Mater. Sci. Eng. A 556 (2012) 331-336

19) L. Chen, H.-S. Kim, S.-K. Kim and B. C. De Cooman: ISIJ Int. 47 (2007) 1804-1812.

20) H. Nakatsu and S. Takaki: J. Jpn. Inst. Metals 60 (1996) 141-148.

21) M. Koyama, T. Sawaguchi and K. Tsuzaki: Tetsu-to-Hagané 98 (2012) 229-236.

22) M. Koyama, T. Sawaguchi and K. Tsuzaki: ISIJ Int. 53 (2013) 323329.

23) M. Koyama, T. Sawaguchi and K. Tsuzaki: Mater. Sci. Eng. A 530 (2011) 659-663.

24) Y. Moriya, T. Sanpei and H. Tagawa: Iron-based shape-memory alloy excellent in shape-memory property, corrosion resistance and hightemperature oxidation resistance, US patent, (1990) p. 4933027.

25) K. Tsuzaki, Y. Natsume, Y. Tomota and T. Maki: Scr. Metall. Mater. 33 (1995) 1087-1092.

26) M. Koyama, T. Sawaguchi and K. Tsuzaki: Philos. Mag. 92 (2012) 3051-3063.

27) M. Koyama, T. Sawaguchi and K. Tsuzaki: Mater. Sci. Eng. A 528 (2011) 2882-2888.

28) K. Ogawa, T. Sawaguchi, T. Kikuchi, M. Koyama and M. Murakami: Proc. Int. Conf. SMST-2007, (ASM International, Ohio, 2008) p. 645.

29) F. X. Yin, S. Takamori, Y. Ohsawa, A. Sato and K. Kawahara: Mater. Trans. 43 (2002) 466-469.

30) Z. Dong, T. Sawaguchi, T. Kikuchi, F. Yin, K. Ogawa, P. Sahu and S. Kajiwara: Mater. Sci. Eng. A 442 (2006) 404-408.

31) H. Otsuka, H. Yamada, T. Maruyama, H. Tanahashi, S. Matsuda and M. Murakami: ISIJ Int. 30 (1990) 674-679.

32) M. Andersson, R. Stalmans and J. Ågren: Acta Mater. 46 (1998) 3883.

33) X. Tian and Y. S. Zhang: Mater. Sci. Eng. A 516 (2009) 73-77. 